\title{
29Si NMR Model Dissolution Study of the Degradation of Reversed Phases for High-Performance Liquid Chromatography
}

Citation for published version (APA):

Scholten, A. B., Haan, de, J. W., Claessens, H. A., Ven, van de, L. J. M., \& Cramers, C. A. (1994). 29Si NMR Model Dissolution Study of the Degradation of Reversed Phases for High-Performance Liquid Chromatography. Analytical Chemistry, 66(22), 4085-4092. https://doi.org/10.1021/ac00094a035

DOI:

10.1021/ac00094a035

Document status and date:

Published: 01/01/1994

Document Version:

Publisher's PDF, also known as Version of Record (includes final page, issue and volume numbers)

Please check the document version of this publication:

- A submitted manuscript is the version of the article upon submission and before peer-review. There can be important differences between the submitted version and the official published version of record. People interested in the research are advised to contact the author for the final version of the publication, or visit the $\mathrm{DOI}$ to the publisher's website.

- The final author version and the galley proof are versions of the publication after peer review.

- The final published version features the final layout of the paper including the volume, issue and page numbers.

Link to publication

\footnotetext{
General rights

- You may freely distribute the URL identifying the publication in the public portal. follow below link for the End User Agreement:

www.tue.nl/taverne

\section{Take down policy}

If you believe that this document breaches copyright please contact us at:

openaccess@tue.nl

providing details and we will investigate your claim.
}

Copyright and moral rights for the publications made accessible in the public portal are retained by the authors and/or other copyright owners and it is a condition of accessing publications that users recognise and abide by the legal requirements associated with these rights.

- Users may download and print one copy of any publication from the public portal for the purpose of private study or research.

- You may not further distribute the material or use it for any profit-making activity or commercial gain

If the publication is distributed under the terms of Article 25fa of the Dutch Copyright Act, indicated by the "Taverne" license above, please 


\title{
${ }^{29}$ Si NMR Model Dissolution Study of the Degradation of Reversed Phases for High-Performance Liquid Chromatography
}

\author{
Alex B. Scholten, Jan W. de Haan, Henk A. Claessens, Leo J. M. van de Ven, and Carel A. Cramers \\ Eindhoven University of Technology, Laboratory of Instrumental Analysis, P.O. Box 513, \\ 5600 MB, Eindhoven, The Netherlands
}

In order to simulate aging under chromatographic conditions, mono-, di-, and trifunctional octyl and octadecyl derivatized reversed-phase high-performance liquid chromatography silicas were exposed to the very aggressive mobile phase-like medium of $6 \mathrm{M} \mathrm{NaOH}$ in $\mathrm{MeOH} / \mathrm{H}_{2} \mathrm{O}(50 / 50 \mathrm{v} / \mathrm{v})$. ${ }^{29} \mathrm{Si} \mathrm{NMR}$ was used to study the dissolution characteristics of these phases by monitoring the concentrations of the dissolving silane and silica structures. Dissolution products of alkylchlorosilanes were used as model compounds for assignment purposes. Octadecyl phases appeared to degrade by dissolution of the silica substrate; octadecylsilane structures were shown to be insoluble under the experimental conditions. Monofunctional octyl phases were shown to deteriorate through initial dissolution of monomeric ligand silane particles, whereas for difunctional octyl phases, the silica backbone appeared to dissolve with the silane ligands still attached. The latter mechanism was also observed for the trifunctional octyl phases, but these phases resemble octadecyl phases, probably because the free ligand silane particles are almost insoluble and the major cause of phase degradation is dissolution of the silica substrate.

Silica gel is by far the most widely used substrate for stationary phases in reversed-phase high-performance liquid chromatography (RP-HPLC). The most important disadvantage of silica gel in liquid chromatography is its hydrolytic instability both at low and especially at high $\mathrm{pH}$ values of the mobile phase. Therefore, there has been a substantial effort to synthesize new chromatographic substrates, mostly organic polymers (in their pure form or immobilized on silica supports), that are more resistant to the extreme mobile phase compositions sometimes necessary to achieve a successful separation of, for example, basic drugs. ${ }^{1}$

Despite several successful results in this area, ${ }^{2-5}$ the overall merits of these polymer substrates do not fully counterbalance the well-known favorable properties of silica gel, i.e., its large surface area which is chemically fairly easy to modify, its high pressure resistance, and, finally, the fact that silica substrates do not suffer from swelling effects. Other research therefore concentrates on improving the hydrolytic stability of RP silicas by developing new derivatization materials and

\footnotetext{
(1) Smith, R. M.; Westlake, J. P.; Gill, R.; Osselton, M. P. D. J. Chromatog $1992,592,85$.

(2) Joseph, J. M. ACS Symp. Ser. 1986, No. 297, 83.

(3) Hirata, N.; Tamura, Y.; Kasai, M.; Yanagihara, Y.; Noguchi, K.J. Chromatog $1992,592,93$.

(4) Cope, M. J.; Davidson, I. E. Analyst 1987, 112, 417

(5) Petro, M.; Berek, D. Chromatographia 1993, 37, 549
}

techniques. ${ }^{6-9}$ The observed improved stability of these reversed phases is apparently based on the better shielding by the attached surface structures, which minimizes the interaction of the silica substrate with the surrounding mobile phase.

${ }^{29} \mathrm{Si}$ CP MAS NMR plays an important role in the characterization of the chromatographic silicas because of its surface selectivity. Since the introduction of this technique for silica NMR analysis, ${ }^{10}$ much research has been done in which the relations between the NMR characteristics of the solid-state silica phases and the chromatographic performance were investigated. ${ }^{11}$ An obvious characteristic of these studies is that properties of the silica surface in the dry solid state are related to chromatographic phenomena taking place under conditions in which the silica particles are suspended in the mobile phase. Previously, a combination of carefully controlled artificial aging of stationary phases for RP-HPLC and chromatographic and physicochemical tests, including solidstate NMR, were carried out by our group. ${ }^{12}$ This, in turn, prompted us to perform experiments on silica phases that were dissolved in a very aggressive "mobile phase-like" liquid in order to study the dissolution behavior of RP-HPLC phases as a function of the length of the ligand alkyl chain. ${ }^{13}$ This earlier study was confined to monofunctional reversed phases only.

It is the aim of the present study to elucidate the influence of the functionality (mono-, di-, or trifunctional) of the original silanizing agent on the dissolution rate and dissolution mechanism of a chromatographic phase at high $\mathrm{pH}$. It is also checked whether a surface treatment of the native silica material prior to derivatization has any measurable effect on the dissolution behavior. Metal impurities are suspected to be a major cause of the imhomogeneity of silica surfaces, leading to highly acidic residual surface silanols and unwanted chromatographic peak broadening and tailing. ${ }^{14}$ Leaching procedures reduce the impurity concentration, thereby providing a more homogeneous silica surface which should also enhance the stability of the chemically bonded phase.

(6) Wirth, M. J.; Fatunmbi, H. O. Anal. Chem. 1992, 64, 2783

(7) Wirth, M. J.; Fatunmbi, H. O. Anal. Chem. 1993, 65, 822.

(8) Kirkland, J. J.; Dilks, C. H., Jr,; Henderson, J. E. LC.GC Int. 1993, 6, 436

(9) Kirkland, J. J.; Glajch, J. L.; Farlee, R. D. Anal. Chem. 1989, 61, 2

(10) Sindorf, D. W.; Maciel, G. E. J. Am. Chem. Soc. 1980, 102, 7606.

(11) Albert, K.; Bayer, E. J. Chromatog. 1991, 544, 345

(12) Hetem, M. J. J.; de Haan, J. W.; Claessens, H. A.; van de Ven, L. J. M.; Cramers, C. A. Anal. Chem. 1990, 62, 2288.

(13) Hetem, M. J. J.; de Haan, J. W.; Claessens, H. A.; van de Ven, L. J. M.; Cramers, C. A.; Wijnen, P. W. J. G.; Kinkel, J. N. Anal. Chem. 1990, 62, 2296.

(14) Nawrocky, J. Chromatographia 1991, 31, 177 
Table 1. Llst of the Stationary Phases Under Study

\begin{tabular}{|c|c|c|c|c|}
\hline notation & silica substrate & silane reagent & $\%$ carbon $(w / w)$ & $\begin{array}{l}\text { surface ligand density } \\
\qquad\left(\mu \mathrm{mol} / \mathrm{m}^{2}\right)\end{array}$ \\
\hline $\mathrm{U}=1 / 8$ & untreated & methoxydimethyl-n-octylsilane & 10.0 & 2.61 \\
\hline $\mathrm{U}-2 / 8$ & untreated & dimethoxymethyl-n-octylsilane & 12.6 & 3.82 \\
\hline $\mathrm{U}-3 / 8$ & untreated & trimethoxy-n-octylsilane & 12.0 & 4.06 \\
\hline $\mathrm{U}-1 / 18$ & untreated & methoxydimethyl- $n$-octadecylsilane & 18.1 & 2.65 \\
\hline $\mathrm{U}-2 / 18$ & untreated & dimethoxymethyl-n-octadecylsilane & 20.4 & 3.27 \\
\hline U-3/18 & untreated & trimethoxy-n-octadecylsilane & 20.0 & 3.37 \\
\hline $\mathrm{T}-1 / 8$ & treated & methoxydimethyl- $n$-octylsilane & 10.7 & 3.39 \\
\hline $\mathrm{T}-2 / 8$ & treated & dimethoxymethyl- $n$-octylsilane & 11.6 & 4.18 \\
\hline $\mathrm{T}-3 / 8$ & treated & trimethoxy-n-octylsilane & 11.9 & 4.85 \\
\hline $\mathrm{T}-1 / 18$ & treated & methoxydimethyl- $n$-octadecylsilane & 18.5 & 3.27 \\
\hline $\mathrm{T}-2 / 18$ & treated & dimethoxymethyl-n-octadecylsilane & 20.7 & 4.01 \\
\hline $\mathrm{T}-3 / 18$ & treated & trimethoxy-n-octadecylsilane & 20.3 & 4.13 \\
\hline
\end{tabular}

Furthermore, some conclusions from our earlier investigations are reconsidered on the basis of new information obtained from the present study in which model experiments play an essential role.

\section{EXPERIMENTAL SECTION}

Materials and Methods. The noncommercial silica phases, made as research samples (Lichrospher $100, d_{\mathrm{p}}=5 \mu \mathrm{m}$ ), were obtained from E. Merck (Darmstadt, Germany). Some surface properties are summarized in Table 1. The specific surface areas of the treated $(T-0)$ and untreated $(\mathrm{U}-0)$ native silica substrates were 309 and $371 \mathrm{~m}^{2} / \mathrm{g}$, respectively. The pore volume of both substrates was $1.2 \mathrm{~mL} / \mathrm{g} .{ }^{15}$ (The exact nature of the surface treatment is confined to the manufacturer's knowledge only.)

Mobile phase-like alkaline solutions $(2,4$, and $6 \mathrm{M} \mathrm{NaOH})$ were prepared by adding respectively 4,8 , and $12 \mathrm{~g}$ of sodium hydroxide ( $99.9 \%$, Boom B.V. Meppel, The Netherlands) to $20 \mathrm{~mL}$ of deionized water (Milli-Q, Millipore Corp.) in a Teflon measuring jug, with cooling in a water bath at ambient temperature. After dissolution of the sodium hydroxide, 20 $\mathrm{mL}$ of methanol (Lichrosolv, Merck AG, Darmstadt, Germany) was added, and finally the solution was filled up to 50 $\mathrm{mL}$ using a previously prepared mixture of methanol/water $(50 / 50 \mathrm{v} / \mathrm{v})$. This $\mathrm{MeOH} / \mathrm{H}_{2} \mathrm{O}$ ratio was chosen for practical reasons; the solution contains enough methanol to assure appropriate wetting of the derivatized silica gels. (In the Conclusions section, the influence of mobile phase composition on bonded phase structure is briefly discussed.) Furthermore, $\mathrm{MeOH} / \mathrm{H}_{2} \mathrm{O}(50 / 50 \mathrm{v} / \mathrm{v})$ is a reasonable "average" chromatographic mobile phase composition.

To suspend the silica phases, $700 \mu \mathrm{L}$ of sodium hydroxide solution was added to an exactly known amount of stationary phase in a glass vial. To assure good mixing of the liquid and solid, the vial was shaken vigorously. After the suspension was degassed by a short ultrasonic treatment $(5-10 \mathrm{~s})$, approximately $350 \mu \mathrm{L}$ was transferred with a syringe through a small opening in the Kel-F cap of a $7 \mathrm{~mm}$ o.d., double air bearing type, zirconia spinner (Bruker $\mathrm{GmbH}$, Rheinstetten, Germany). The spinner cap was previously glued to the inside spinner wall, and the opening was closed with a conical Kel-F stopper. This construction showed no leakage of fluid which could otherwise easily damage the NMR probe head. The

(15) Houben-Michalková, A. Study of Aging Processes of Chemically Modified Silica Substrates in Liquid Chromatography; CIP Data, Royal Library: The Hague, The Netherlands, 1992. total amount of suspension in the NMR sample holder was weighed and then transferred to the NMR spectrometer as quickly as possible.

NMR Experiments. ${ }^{29} \mathrm{Si}$ NMR measurements were performed on a Bruker MSL-400 NMR spectrometer at a Larmor frequency of $79.4 \mathrm{MHz}$. The samples were spun at a frequency of $800 \mathrm{~Hz}$ to minimize any broadening due to dipolar interactions in the viscous liquids. Flip angles of $45^{\circ}$ were applied with an acquisition time of $40 \mathrm{~ms}$, and the pulse interval time was set to $5 \mathrm{~s}$. This relatively short pulse delay time was chosen to ensure that only dissolved silica particles (with small $T_{1}$ values) are detected, thus avoiding disturbing signals from any remaining solid phase or precipitated particles. A total of 360 FIDs were accumulated, resulting in a time resolution of $0.5 \mathrm{~h}$ per spectrum. Typically, 40 spectra were recorded per dissolution experiment. The raw FIDs were zero-filled to $8 K$, and prior to Fourier transformation a line broadening of $20 \mathrm{~Hz}$ was applied. Unless stated otherwise, intensity scales of all spectra were normalized to the scale of the spectrum of the native silica gel $\mathrm{U}-0$ in $6 \mathrm{M} \mathrm{NaOH}$ in $\mathrm{MeOH} / \mathrm{H}_{2} \mathrm{O}(50 /$ $50 \mathrm{v} / \mathrm{v}$ ) after $20 \mathrm{~h}$ of dissolution. Reported chemical shifts are referenced to liquid tetramethylsilane, using $\mathrm{Q}_{8} \mathrm{M}_{8}$ (the trimethylsilyl ester of cubic octameric silicate) as an external reference.

Optimization of the Dissolution Conditions. In order to obtain a useful NMR signal to noise ratio in combination with a solvent composition that as closely as possible approximates true chromatographic mobile phases, the sodium hydroxide concentration and the $\mathrm{Na}$ :Si ratio of the suspensions had to be optimized. As ${ }^{29} \mathrm{Si}$ NMR generally lacks high sensitivity, a high $\mathrm{pH}$ will be necessary to promote dissolution of a large quantity of reversed-phase material. However, if the sodium hydroxide concentration is too high, dissolution will be very fast and the time required to obtain a single NMR spectrum will be too long to allow observation of the mechanism through which the dissolution has proceeded. On the other hand, a too low $\mathrm{Na}: \mathrm{Si}$ ratio allows only large polymeric silica structures to be dissolved, and then little can be concluded about the initial monomeric molecular structures leaving the reversed-phase surface. Therefore, several experiments were carried out in which the sodium hydroxide concentration as well as the amount of reversed-phase material was varied before the real dissolution experiments were conducted. To illustrate the considerations above, Figure 1 displays ${ }^{29} \mathrm{Si}$ NMR spectra of suspensions of $\mathrm{U}-1 / 8$ in which the sodium hydroxide 


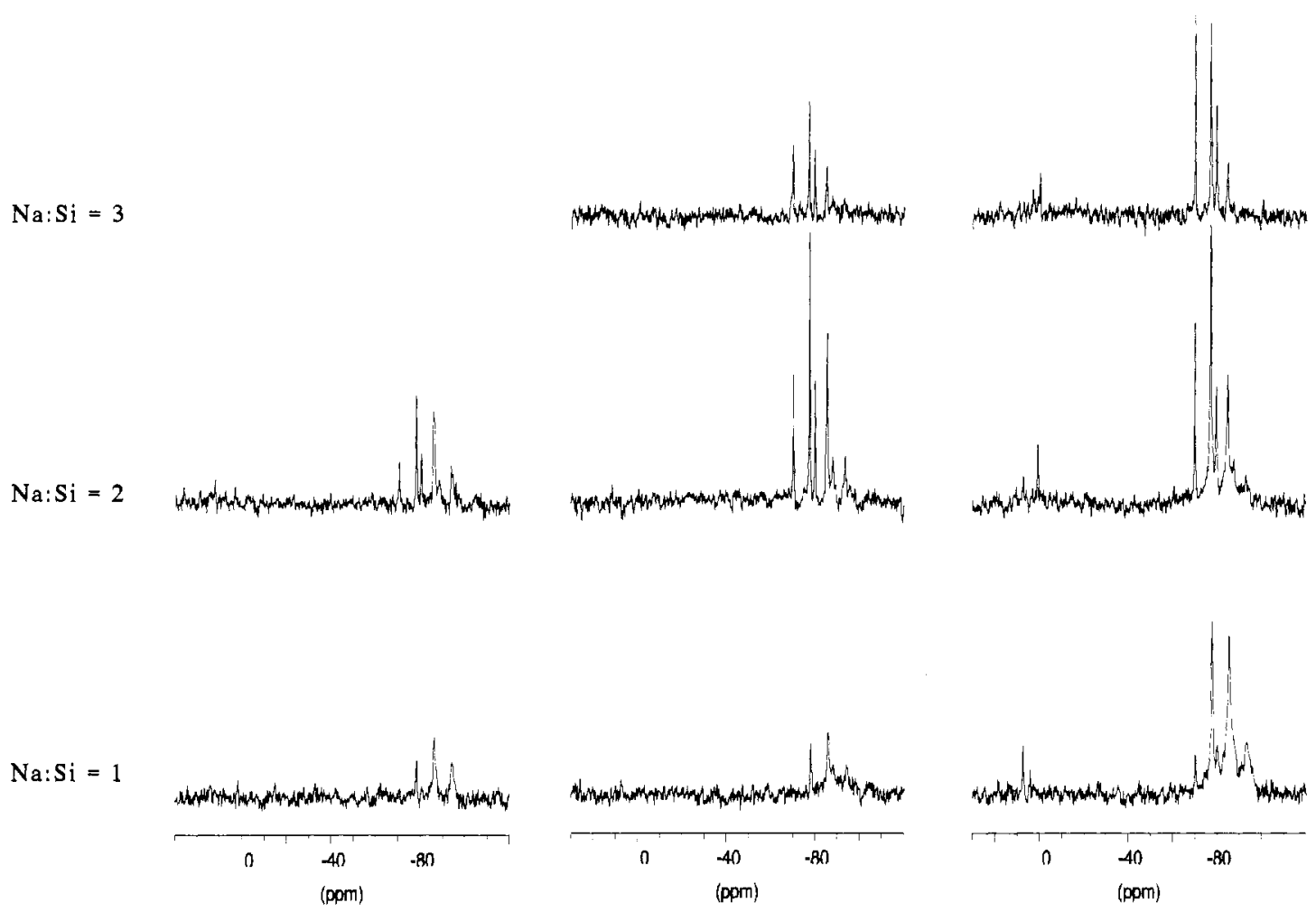

Figure 1. ${ }^{29} \mathrm{SI} \mathrm{NMR} \mathrm{spectra} \mathrm{of} \mathrm{suspensions} \mathrm{of} \mathrm{the} \mathrm{phase} \mathrm{U-1/8} \mathrm{in} \mathrm{alkaline} \mathrm{MeOH} / \mathrm{H}_{2} \mathrm{O}(50 / 50 \mathrm{v} / \mathrm{v})$ after $5 \mathrm{~h}$ of dissolution. Horizontally, the sodium hydroxide concentration is varied, and in the vertical direction the Na:Si ratio is varied.

concentration was varied between 2,4 , and $6 \mathrm{M}$ in combination with $\mathrm{Na}: \mathrm{Si}$ ratios that were 1,2 , and 3 , respectively. A compromise between signal intensity and dissolution rate was found with a combination of a $6 \mathrm{M} \mathrm{NaOH}$ in $\mathrm{MeOH} / \mathrm{H}_{2} \mathrm{O}$ $(50 / 50 \mathrm{v} / \mathrm{v})$ solution and a $\mathrm{Na}: \mathrm{Si}$ ratio of 2 . This combination will be used throughout this study. Such a highly alkaline solution obviously will not be useful as a mobile phase in everyday chromatographic practice. In the present study, rather bold circumstances are chosen on purpose, so as to obtain useful results within a reasonable time.

Model Experiments. The assignment of the observed ${ }^{29} \mathrm{Si}$ nuclear magnetic resonances to specific ligand silane structures was performed by using model experiments in which alkylchlorosilanes were used. For example, methyl-n-octyldichlorosilane was added to a $6 \mathrm{M} \mathrm{NaOH}$ in $\mathrm{MeOH} / \mathrm{H}_{2} \mathrm{O}(50 / 50$ $\mathrm{v} / \mathrm{v}$ ) solution to obtain information on the ligand silane signals observed after dissolution of difunctional octyl phases in the same medium. The added amount of chlorosilane always corresponded to the total amount of ligand structures introduced by dissolving the original phase. To study the influence of the presence of silicate structures on the chemical shift and intensity patterns of the ligand signals, native silica gel was dissolved in an equilibrated solution of the corresponding model silane in $6 \mathrm{M} \mathrm{NaOH}$ in $\mathrm{MeOH} / \mathrm{H}_{2} \mathrm{O}(50 /$ $50 \mathrm{v} / \mathrm{v})$. Chlorosilanes were purchased from different suppliers, used as received, and stored under an argon atmosphere.

\section{RESULTS AND DISCUSSION}

Silica Substrate. Table 2 lists the NMR chemical shifts of the various silicate species that occur in alkaline silicate

\begin{tabular}{lcc}
\hline $\begin{array}{l}\text { Table 2. Sillcate Structures Present in } 6 \mathrm{M} \\
\text { (50/50 v/v) Solutions, Thelr Notation, and Thelr Chemical Shift }\end{array}$ \\
$\begin{array}{l}\text { Externally Referenced to Liquid Tetramethylellane } \\
\text { silicate structure } \\
\text { notation }\end{array}$ & $\delta(\mathrm{ppm})$ \\
tetrahydroxysilane & $\mathrm{Q}^{0}$ & -70.0 \\
hexahydroxydisiloxane & $\mathrm{Q}_{2}^{1}$ & -77.0 \\
hexahydroxycyclotrisiloxane & $\mathrm{Q}_{\nabla}^{2}$ & -79.7 \\
dihydroxydisiloxysilane (linear oligomer) & $\mathrm{Q}^{2}$ & -84.7 \\
hydroxytrisiloxysilane & $\mathrm{Q}_{\nabla}^{3}$ & -87.4 \\
(part of trisiloxane ring structure) & $\mathrm{Q}^{3}$ & -92.5 \\
hydroxytrisiloxysilane & & \\
a From ref 16. & & \\
\hline
\end{tabular}

solutions. Figure 2 displays the spectrum of a suspension of $\mathrm{U}-0$ in a $6 \mathrm{M} \mathrm{NaOH}$ in $\mathrm{MeOH} / \mathrm{H}_{2} \mathrm{O}(50 / 50 \mathrm{v} / \mathrm{v})$ solution after $20 \mathrm{~h}$ of dissolution. The relative signal intensities of the various silicate species are in good agreement with those reported in the literature for an equilibrium solution with a $\mathrm{Na}$ :Si ratio of 2.17 In Figure 3, the signal intensities are plotted as a function of dissolution time for both native silicas U-0 (Figure $3 \mathrm{a}$ ) and T-0 (Figure 3b). It can be seen that under our experimental conditions no effect from the surface treatment can be discerned. Actually, this effect could not be observed for any of the phases listed in Table 1. As a consequence, further results and discussion are focused on the phases bonded on the untreated silica substrate, while all conclusions are equally valid for the phases bonded on the

(16) Engelhardt, G;; Zeigan, D.; Jancke, H.; Hoebbel, D.; Wieker, W. Z. Anorg. Allg. Chem. 1975, $418,17$.

(17) Williams, E. A.; Cargioli, J. D. Annu. Rep. NMR Spectrosc. 1979, 9, 260. 


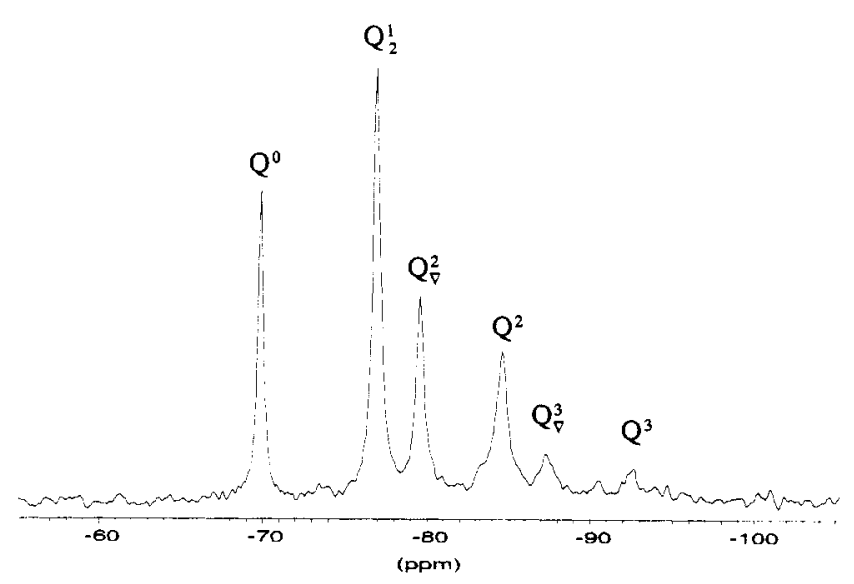

Figure 2. ${ }^{29} \mathrm{Si} \mathrm{NMR}$ spectrum of $\mathrm{U}-0$ after $20 \mathrm{~h}$ of dissolution in $6 \mathrm{M}$ $\mathrm{NaOH}$ in $\mathrm{MeOH} / \mathrm{H}_{2} \mathrm{O}(50 / 50 \mathrm{v} / \mathrm{v})$.
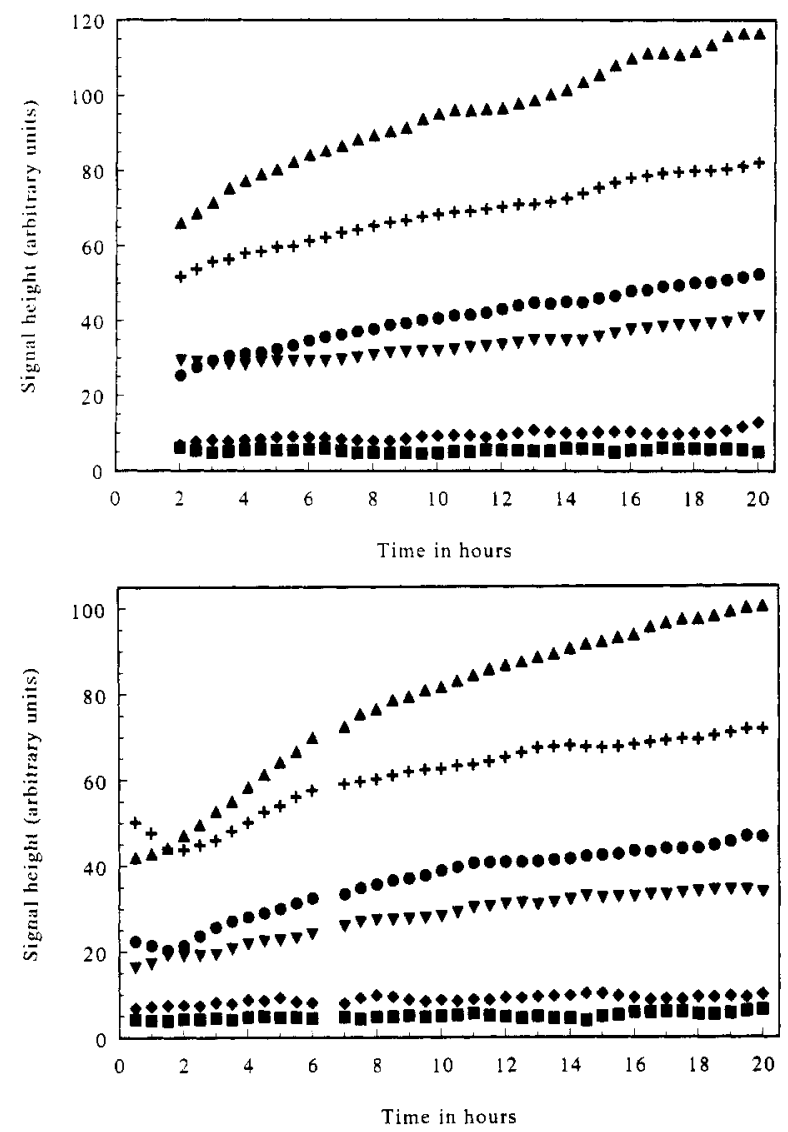

Figure 3. Helghts of the ${ }^{29} \mathrm{SI}$ NMR signals of the silicate structures of the natlve sillcas $U-0(a$, top) and $T-0(b$, bottom) as a function of dissolution time in $6 \mathrm{M} \mathrm{NaOH}$ in $\mathrm{MeOH} / \mathrm{H}_{2} \mathrm{O}(50 / 50 \mathrm{v} / \mathrm{v})$. A 3-point moving average was used to smooth the curves $\left(+, Q_{0} ; \Delta, Q_{2}^{1} ; \bullet\right.$, $Q_{\nabla}^{2} ; \nabla, Q^{2} ; \bullet, Q_{\nabla}^{3} ; \mathbf{D}, Q^{3}$ ).

treated silica substrate. The dissolution circumstances probably are too severe to allow detection of subtle differences in surface properties due to the pretreatment. (These subtle differences are present, because chromatographically the phases on the treated silica substrate were shown to be generally more stable. ${ }^{15}$ ) Due to the rapid dissolution and chemical exchange between the different silicate structures in solution, ${ }^{18}$ any small initial difference in relative peak intensities is averaged out very quickly (at the most within a few minutes).

(18) Knight, C. T. G.; Kirkpatrick, R. J.; Oldfield, E. J. Magn. Reson. 1988, 78 31 .

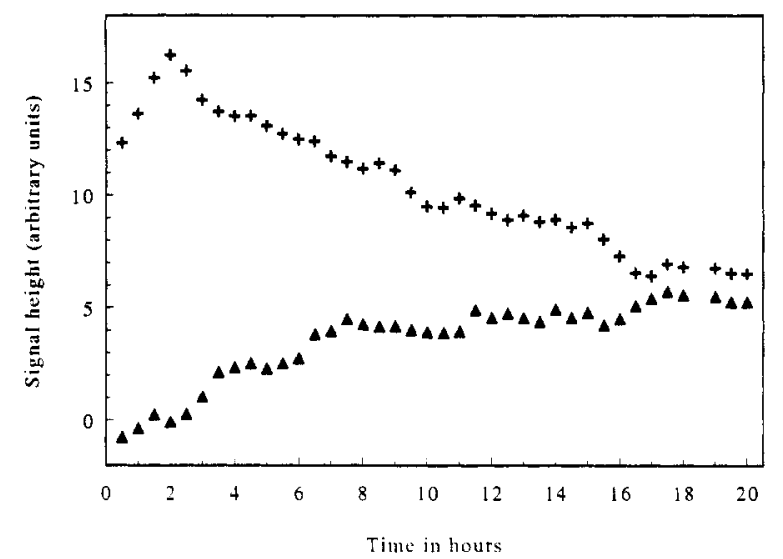

Figure 4. Heights of the ${ }^{29} \mathrm{SI} N \mathrm{NR}$ signals of the $U-1 / 8$ ligand sllane structures as a function of dissolution time in $6 \mathrm{M} \mathrm{NaOH}$ in $\mathrm{MeOH} / \mathrm{H}_{2} \mathrm{O}$ $(50 / 50 \mathrm{v} / \mathrm{v})$. A 3-point moving average was used to smooth the curves $(+,-0.1 \mathrm{ppm} ; \boldsymbol{\Delta},+7.3 \mathrm{ppm})$.

Monofunctional Phases. After suspension of the monofunctional $\mathrm{C}_{8}$ phase $\mathrm{U}-1 / 8$, two extra resonances could be observed in the ${ }^{29} \mathrm{Si}$ NMR spectra, apart from the silica pattern in the -70 to -100 ppm range which is similar to that of $U-0$. The chemical shifts of the corresponding ${ }^{29} \mathrm{Si}$ nuclei are +7.3 and $-0.1 \mathrm{ppm}$. Figure 4 displays the peak heights of these signals as a function of dissolution time. The shape of both curves suggests that the species resonating at $-0.1 \mathrm{ppm}$ is formed immediately after suspension of the derivatized silica and then reacts to give the species resonating at $+7.3 \mathrm{ppm}$. Figure 5 displays the ${ }^{29} \mathrm{Si}$ NMR spectra from which these two resonances can be assigned to specific silane structures. There is no doubt that the species detected in the solution of dimethyl$n$-octylchlorosilane in $6 \mathrm{M} \mathrm{NaOH}$ in $\mathrm{MeOH} / \mathrm{H}_{2} \mathrm{O}(50 / 50$ $v / v)$ shown in Figure $5 b$ is dimethyl-n-octylhydroxysilane $\left(\mathrm{M}^{0}\right)$, resonating at $-1.6 \mathrm{ppm}$. It seems logical to ascribe the resonance at $+7.3 \mathrm{ppm}$ in Figure $5 \mathrm{e}$ and $\mathrm{f}$ to $1,1,2,2$ tetramethyl-1,2-di-n-octyldisiloxane $\left(\mathrm{M}_{2}^{1}\right)$, but the hexamethyldisiloxane dimer is seen to hydrolyze to the hydroxy monomer in the alkaline environment (Figure $5 \mathrm{c}$ and d). From a comparison of Figure $5 \mathrm{~b}$ and $\mathrm{e}$, it must be concluded that when $\mathrm{U}-0$ is added to a solution of dimethyl-n-octylchlorosilane in $6 \mathrm{M} \mathrm{NaOH}$, a fast condensation reaction occurs between $\mathbf{M}^{0}$ and silicate species, forming dimethyl- $n$-octylsiloxysilane $\left(\mathrm{M}^{1}\right)$ structures. The silane part of these structures then gives rise to a signal at $+7.3 \mathrm{ppm}$.

These findings differ from our earlier conclusions, which stated that the free ligand $\left(\mathrm{M}^{0}\right)$ resonates at $+18 \mathrm{ppm} .{ }^{13}$ This previous assignment was based on the chemical shift of trimethylethoxysilane (to be found in literature). ${ }^{19}$ However, the hydroxy compound in a highly alkaline solution will ionize to a large extent, contrary to the alkoxy analogue. This ionization increases the electron density around the silicon nucleus, and thus the NMR signal is shifted to higher field (lower ppm value), from +18 to $-0.5 \mathrm{ppm}$. This large upfield shift was observed earlier by Williams et al. in a study of the solvent effects on the chemical shifts of silanols. ${ }^{20}$

Our earlier conclusion that the $+7.3 \mathrm{ppm}$ signal is due to the dimeric ligand molecule $\mathbf{M}_{2}^{1}$ was only partly correct. This

(19) Engelhardt, G.; Jancke, H.; Măgi, M.; Pehk, T.; Lippmaa, E. J. J. Organomet. Chem. 1971, 28, 293.

(20) Williams, E. A.; Cargioli, J. D.; Larochelle, R. W. J. Organomet. Chem. 1976, 108,153 . 


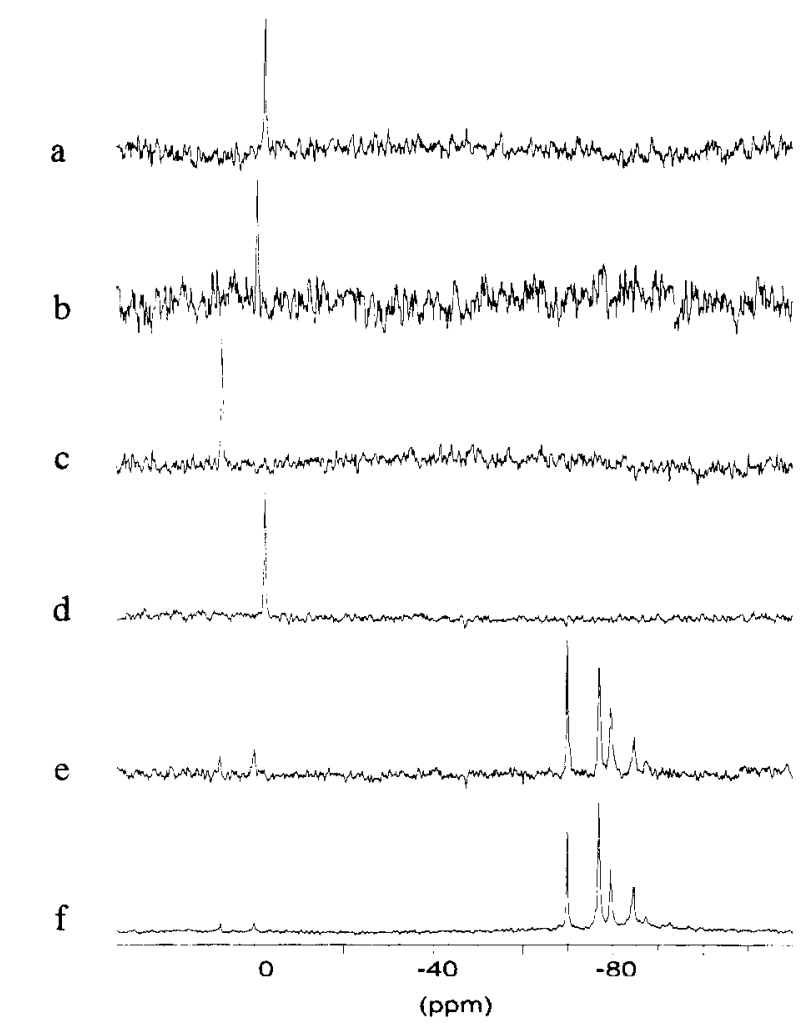

Flgure 5. ${ }^{28} \mathrm{SI}$ NMR spectra of (a) trimethylchlorosilane; (b) dimethyln-octylchlorosilane; (c) hexamethyldisiloxane immediately after dissolution and (d) after $48 \mathrm{~h}$ of dissolution in $6 \mathrm{M} \mathrm{NaOH}$ in $\mathrm{MeOH} / \mathrm{H}_{2} \mathrm{O}$ $(50 / 50 \mathrm{v} / \mathrm{v}) ;(\theta)$ dimethyl-n-octylchlorosilane $0.5 \mathrm{~h}$ after addltion of $\mathrm{U}-0$ in $6 \mathrm{M} \mathrm{NaOH}$ in $\mathrm{MeOH} / \mathrm{H}_{2} \mathrm{O}(50 / 50 \mathrm{v} / \mathrm{v}$ ); and (f) an equilibrium solution of $\mathrm{U}-1 / 8$ in $6 \mathrm{M} \mathrm{NaOH}$ in $\mathrm{MeOH} / \mathrm{H}_{2} \mathrm{O}(50 / 50 \mathrm{v} / \mathrm{v})$. Intensity scales of the separate spectra are adjusted to fit the figure dimensions.

study proves that in $6 \mathrm{M} \mathrm{NaOH}$ in $\mathrm{MeOH} / \mathrm{H}_{2} \mathrm{O}(50 / 50 \mathrm{v} / \mathrm{v})$, dimeric monofunctional ligand particles (Figure $5 \mathrm{c}$ ) and $\mathbf{M}^{1}$ structures cannot be distinguished on the basis of ${ }^{29} \mathrm{Si} \mathrm{NMR}$ chemical shifts. The major part of the $+7.3 \mathrm{ppm}$ signal must be caused by $\mathbf{M}^{1}$ structures, because it is highly unlikely that dimeric ligand particles are formed, whereas siloxane silicate particles are by far the most abundant in solution. Thus the probability of two monomeric ligand species encountering each other before reacting with, for example, tetrahydroxysilane $\left(\mathrm{Q}^{0}\right)$ is remote.

Now, after the assignments made above, Figure 4 seems to indicate that deterioration of monofunctional $\mathrm{C}_{8}$ phases occurs largely through initial dissolution of monomeric ligand silane species.

Upon dissolution of the monofunctional $\mathrm{C}_{18}$ phase (U-1/ 18), no ligand signals were observed. Most likely this is caused by the very low solubility of dimethyl- $n$-octadecylhydroxysilane species in the alkaline methanol/water solution. Figure 6 illustrates this by comparing respectively equilibrium solutions of trimethylchlorosilane in a U-0 suspension, a U-1/8 suspension, and a $U-1 / 18$ suspension. Trimethylhydroxysilane is very well soluble in the $6 \mathrm{M} \mathrm{NaOH}$ solution, whereas dimethyl- $n$-octylhydroxysilane and dimethyl- $n$-octylsiloxysilane $\left(\mathrm{M}^{0}\right.$ and $\left.\mathrm{M}^{1}\right)$ are present in their equilibrium concentrations. Octadecyl species are apparently insoluble under the experimental conditions because of the long, apolar alkyl chain that cannot be accommodated well enough by the polar solvent medium. As a consequence, degradation of monofunctional $\mathrm{C}_{18}$ phases for RP-HPLC most likely takes place by dissolution

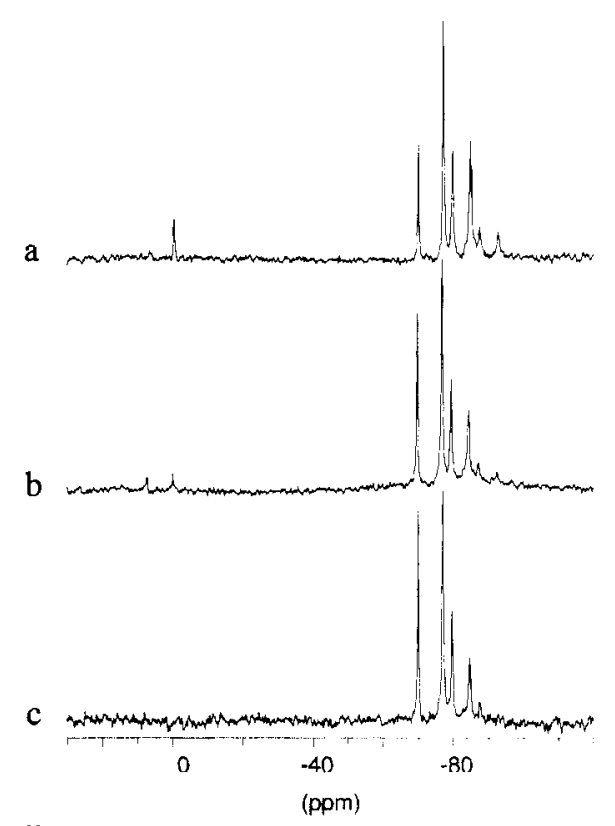

Figure 6. ${ }^{29} \mathrm{Si}$ NMR spectra of equillbrium solutions of (a) $U-0$ in $6 \mathrm{M}$ $\mathrm{NaOH} \mathrm{MeOH} / \mathrm{H}_{2} \mathrm{O}(50 / 50 \mathrm{v} / \mathrm{v})$ after addition of trimethylchlorosilane; (b) $\mathrm{U}-1 / 8$ and (c) $\mathrm{U}-1 / 18$ in $6 \mathrm{M} \mathrm{NaOH} \mathrm{MeOH} / \mathrm{H}_{2} \mathrm{O}(50 / 50 \mathrm{v} / \mathrm{v})$.

of the underlying silica substrate and not by a mechanism in which octadecylsilanes are stripped off from the surface.

Interesting to note is the increasing $Q^{0} / Q_{2}^{1}$ ratio in the spectra of Figure 6 when going from the mimicked suspension of a monofunctional $C_{1}$ phase to the $C_{18}$ phase suspension. Probably, the amount of dissolved ligand species in solution determines the $\mathrm{Na}: \mathrm{Si}$ ratio expressed by the intensity distribution in the silicate signal region. No octadecyl ligands are observed in solution, and consequently the silicate pattern of Figure $6 \mathrm{c}$ is the one with the highest $Q^{0} / Q_{2}^{1}$ ratio.

Difunctional Phases. Dissolution of the difunctional $\mathrm{C}_{8}$ phase (U-2/8) gives rise to two ligand signals at -14.0 and $-22.8 \mathrm{ppm}$. The assignments of these resonances to specific silane structures can be made in analogy with the strategy described for the monofunctional phases. This is illustrated in Figure 7. Clearly, the resonance at $-14.0 \mathrm{ppm}$ in Figure 7a stems from dimethyldihydroxysilane, while the $-22.8 \mathrm{ppm}$ signal in Figure $7 \mathrm{~b}$ is due to the presence of 1,2-dimethyl1,2-di- $n$-octyl-1,2-dihydroxysiloxane $\left(D_{2}^{1}\right)$. Apparently, the difunctional ligand species with the longer alkyl chain is more likely to dimerize in solution (compare Figures $7 \mathrm{a}$ and $7 \mathrm{~b}$ ). In Figure 7c, however, the $-14.0 \mathrm{ppm}$ signal must belong to the molecule methyl- $n$-octylhydroxysiloxysilane $\left(D^{1}\right)$ because of the abundance of silicate structures in solution. This assumption is supported by the fact that after addition of $\mathrm{U}-0$ to a suspension of methyl- $n$-octyldichlorosilane, only the -22 ppm signal initially is broadened and sharpened again after a few hours, while the $-14 \mathrm{ppm}$ signal remains unaffected. This successive broadening and sharpening (not shown in the figures) can be explained by the conversion of the dimer $D_{2}^{1}$ into $D^{1}$ species as soon as silicate particles interfere with the dynamic equilibrium between mono- and dimer ligand particles.

Figure 8 illustrates that, after a difunctional $\mathrm{C}_{8}$-phase is suspended, equilibrium between the two ligand species is attained very fast. After $2 \mathrm{~h}$ of dissolution, the ratio of the 


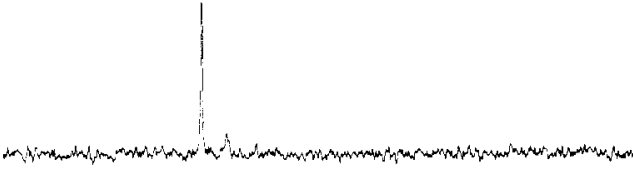

b

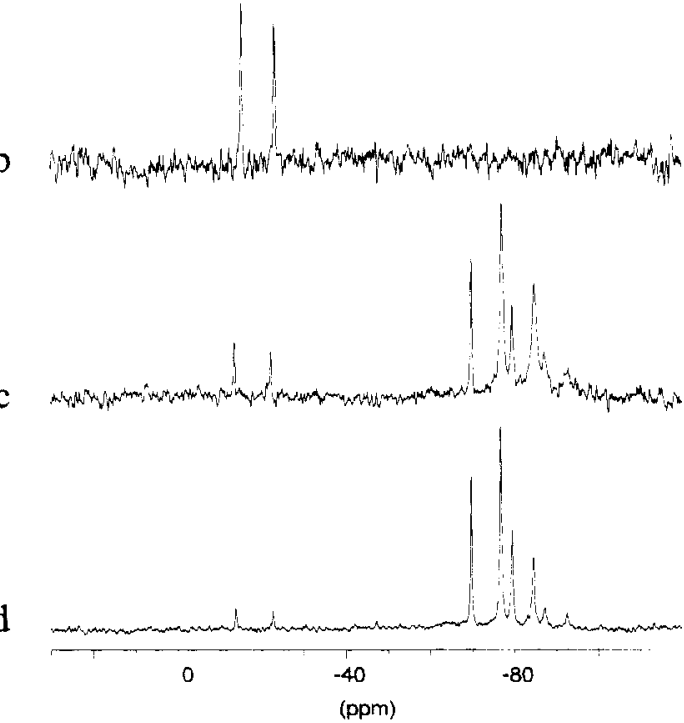

Flgure 7. ${ }^{29}$ SINMR spectra of (a) dimethyldichlorosilane and (b) methyln-octyldichlorosilane in $6 \mathrm{M} \mathrm{NaOH}$ in MeOH/ $\mathrm{H}_{2} \mathrm{O}(50 / 50 \mathrm{v} / \mathrm{v})_{\text {; }}$ (c) methyt n-octyllichlorosilane $12 \mathrm{~h}$ after addition of $\mathrm{U}-0$ in $6 \mathrm{M} \mathrm{NaOH}$ in MeOH/ $\mathrm{H}_{2} \mathrm{O}(50 / 50 \mathrm{v} / \mathrm{v})$; and (d) equilibrium solution of U-2/8 in $6 \mathrm{M} \mathrm{NaOH}$ in $\mathrm{MeOH} / \mathrm{H}_{2} \mathrm{O}(50 / 50 \mathrm{v} / \mathrm{v})$. Intensity scales of the separate spectra are adjusted to fit the figure dimensions.

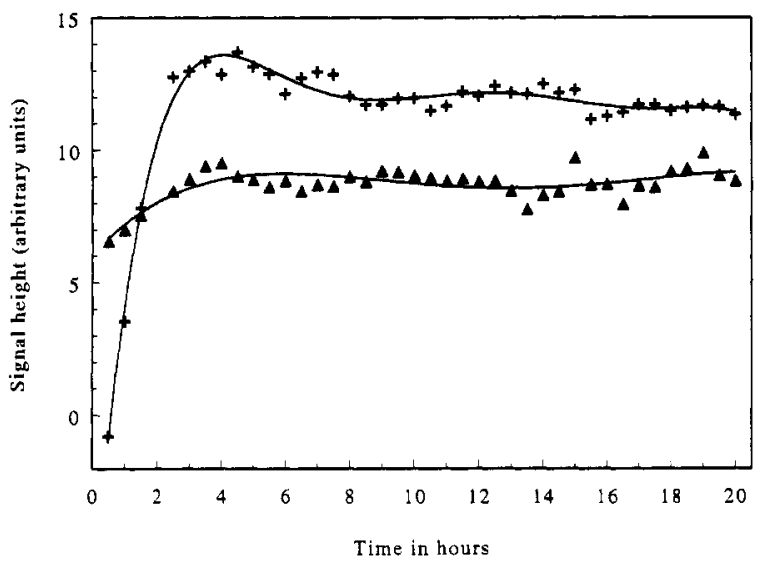

Figure 8. Helghts of the ${ }^{29} \mathrm{SI}$ NMR signals of the U-2/8 ligand sllane structures as a function of dissolution time in $6 \mathrm{M} \mathrm{NaOH}$ in MeOH/ $/ \mathrm{H}_{2} \mathrm{O}$ $(50-/ 50 \mathrm{v} / \mathrm{v})$. A 3-point moving average was used to smooth the curves $\left(+, D^{0} ; \Delta, D^{1}, D_{2}^{1}\right)$. The lines drawn are only a gulde to the eye.

signal heights of the two ligand species remains constant. Important to note is that during the first hour, the $\mathrm{D}^{1}$ signal intensity is higher than that of $D^{0}$. This implies that the initial dissolution mechanism proceeds through hydrolysis of oligomeric (or at least dimeric) silane structures. Unfortunately, a ligand dimer $D_{2}^{1}$ cannot be distinguished from a $D^{1}$ structure (vide supra), and thus it cannot be stated whether the alkaline solution in the first instance strips off only ligand dimers, ligand structures attached to a small silica backbone particle, or a combination of both. However, difunctional derivatization agents are not known to form extensive polymer layers on a

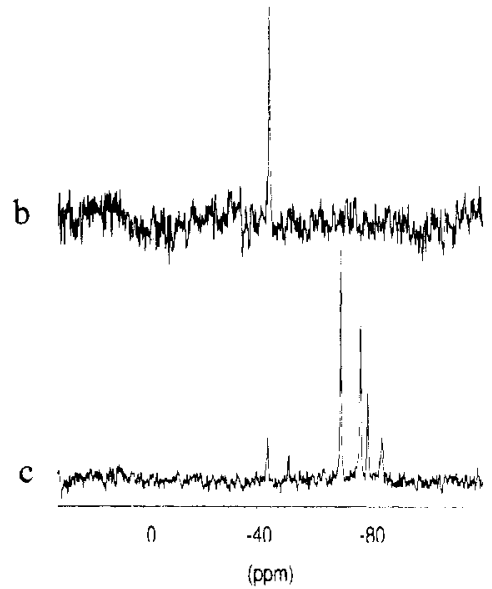

Figure 9. ${ }^{29}$ Si NMR spectra of (a) n-octyltrichlorosilane in $6 \mathrm{M} \mathrm{NaOH}$ in MeOH/ $\mathrm{H}_{2} \mathrm{O}$ (50/50 v/v); number of scans, 360; (b) number of scans, 5000; (c) U-3/8 $0.5 \mathrm{~h}$ after dissolution in $6 \mathrm{M} \mathrm{NaOH}$ in $\mathrm{MeOH} / \mathrm{H}_{2} \mathrm{O}$ $(50 / 50 \mathrm{v} / \mathrm{v})$. Intensity scales of the separate spectra are adjusted to fit the figure dimensions.

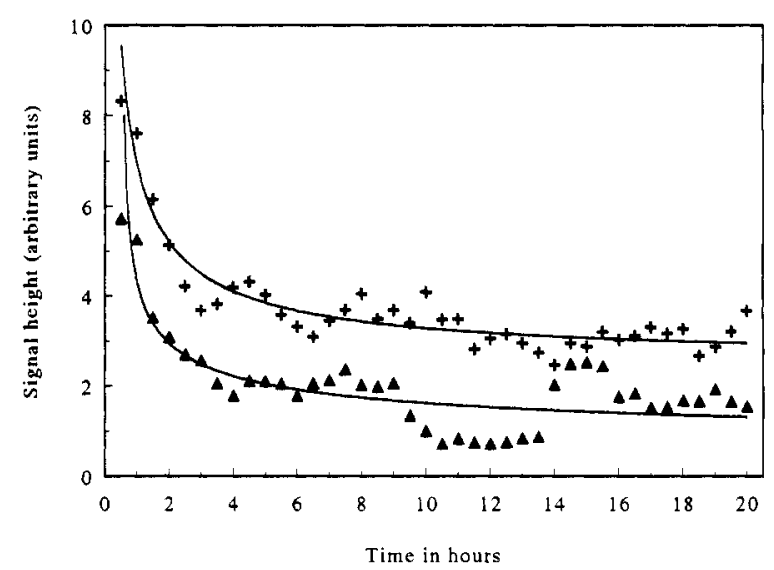

Figure 10. Heights of the ${ }^{29} \mathrm{SINMR}$ signals of the U-3/8 ligand silane structures as a function of dissolution time in $6 \mathrm{M} \mathrm{NaOH}$ in $\mathrm{MeOH} / \mathrm{H}_{2} \mathrm{O}$ $(50 / 50 \mathrm{v} / \mathrm{v})$. A 3-point moving average was used to smooth the curves $\left(+, T^{0} ; \Delta, T^{1}, T_{2}^{1}\right)$. The lines drawn are only a guide to the eye.

silica surfaces, ${ }^{21}$ and therefore it seems most likely that the silica backbone is dissolved with the silane ligand still chemically attached. As already stated, no ligand species can be observed after dissolution of the difunctional octadecyl phase U-2/18.

Trifunctional Phases. In Figure $9 c$, the ${ }^{29} \mathrm{Si}$ NMR spectrum of the trifunctional phase $\mathrm{U}-3 / 8$ is shown after $0.5 \mathrm{~h}$ of dissolution. Again, clearly two ligand signals are observed. Figure 10 shows the rapid disappearance of these signals. The peak assignment can again be made by dissolving the appropriate derivatizing agent in the $6 \mathrm{M} \mathrm{NaOH}$ in $\mathrm{MeOH} /$ $\mathrm{H}_{2} \mathrm{O}(50 / 50 \mathrm{v} / \mathrm{v})$ solution (see Figure 9). After addition of $n$-octyltrichlorosilane to a $6 \mathrm{M} \mathrm{NaOH}$ in $\mathrm{MeOH} / \mathrm{H}_{2} \mathrm{O}(50 /$ $50 \mathrm{v} / \mathrm{v}$ ) solution, immediately a white precipitate is formed; after 360 scans, no significant NMR signal can be observed. After 5000 scans, a signal at $-44.2 \mathrm{ppm}$ is apparent which should be ascribed to the monomer $n$-octyltrihydroxysilane $\left(\mathrm{T}^{0}\right)$. This assignment is in accordance with results of Hasegawa et al., who found the corresponding methyl analogue to resonate at $-42.1 \mathrm{ppm}$ in an aqueous $2 \mathrm{M}$ sodium hydroxide

(21) Pfleiderer, B.; Albert, K.; Bayer, E. J. Chromatogr. 1990, 506, 343. 


\begin{tabular}{|c|c|c|}
\hline ligand silane species & notation ${ }^{a}$ & $\delta(\mathrm{ppm})$ \\
\hline $\begin{array}{l}\text { dimethyl-n-octylhydroxysilane } \\
\text { dimethyl- } n \text {-octylsiloxysilane } \\
\text { 1,1,2,2-tetramethyl-1,2-di- } n \text {-octyldisiloxane }\end{array}$ & $\begin{array}{l}\mathbf{M}^{\mathbf{0}} \\
\mathbf{M}^{1} \\
\mathbf{M}_{\mathbf{2}}^{1}\end{array}$ & $\begin{array}{l}-1 \\
+7 \\
+7\end{array}$ \\
\hline $\begin{array}{l}\text { methyl- } n \text {-octyldihydroxysilane } \\
\text { methyl- } n \text {-octylhydroxysiloxysilane } \\
\text { 1,2-dimethyl-1,2-di- } n \text {-octyl- } \\
\text { 1,2-dihydroxydisiloxane }\end{array}$ & $\begin{array}{l}D^{0} \\
D^{1} \\
D_{2}^{1}\end{array}$ & $\begin{array}{l}-14 \\
-23 \\
-23\end{array}$ \\
\hline $\begin{array}{l}n \text {-octyltrihydroxysilane } \\
n \text {-octyldihydroxysiloxysilane } \\
1,2 \text {-di-n-octyl-1,1,2,2-tetrahydroxydisiloxane }\end{array}$ & $\begin{array}{l}T^{0} \\
T^{1} \\
T_{2}^{1}\end{array}$ & $\begin{array}{l}-44 \\
-52 \\
-52\end{array}$ \\
\hline \multicolumn{3}{|l|}{ - See also Figure 11 for structural illustration. } \\
\hline
\end{tabular}

solution. ${ }^{22}$ The small upfield shift of $\mathrm{T}^{0}$ under our experimental conditions probably is caused by an increased ionization in the more alkaline solution. The signal at $-51.6 \mathrm{ppm}$ in Figure 9 cindicates the presence of $n$-octyldihydroxysiloxysilane $\left(\mathrm{T}^{1}\right)$ moieties. It cannot be ruled out, however, that the oligomeric ligand particle $T_{2}^{1}$ also contributes to the NMR signal, because trifunctional silanizing reagents are known to form polymeric surface layers through cross-linking. This could result in an initial dissolution of dimeric ligand particles. Nevertheless, both the very low solubility of n-octyltrihydroxysilane and the rapidly decreasing ligand signals after dissolution of a trifunctional octyl phase support the idea that deterioration of trifunctional phases takes place mainly through dissolution of the underlying silica substrate, while ligand silane moieties remain attached to the dissolving silicate particles. If dissolution of the silica substrate is the main cause of stationary phase degradation, carbon contents are seen to increase upon aging. ${ }^{23,24}$ This was actually observed after chromatographic aging experiments with the trifunctional $\mathrm{C}_{8}$ phase discussed here. ${ }^{15}$

Chemical Shifts of the Detected Silane Species. Table 3 summarizes all ligand species that were detected after dissolution of the mono-, di-, and trifunctional $\mathrm{C}_{8}$ phases, and Figure 11 gives a structural illustration. A remarkable feature is observed when comparing the chemical shifts of the monoand difunctional monomeric ligand silane molecules with their respective dimeric species. The monomeric monofunctional ligand silane particle $\mathbf{M}^{0}$ has a decreased chemical shift compared to its dimer $\mathrm{M}_{2}^{1}$, while for the monomeric difunctional ligand silane particle $\mathrm{D}^{0}$, an increase is observed. When the chemical shifts of the corresponding methoxysilanes are considered, the chemical shifts of the hydroxysilanes in alkaline solution can be understood by taking in to account an ionization and a hydrogen-bonding contribution to the NMR chemical shift when a methoxy group is substituted for a hydroxyl group (Table 4). In their neutral form, hydroxysilanes have chemical shifts comparable to those of their alkoxy analogues. Ionization of trialkylhydroxysilane induces a shielding of about 18

(22) Hasegawa, I.; Sakka, S.; Sugahara, Y.; Kuroda, K.; Kato, C. J. Ceramic Assoc. Jpn. 1990, 98, 647.

(23) Hetem, M.; van de Ven, L. J.; de Haan, J. W.; Cramers, C. A.; Albert, K.; Bayer, E. J. Chromatogr. 1989, 479, 269.

(24) Engelhardt, H.; Löw, H.; Eberhardt, W.; Mauss, M. Chromatographia 1989 27,535 .

(25) Williams, E. A.; Cargioli, J. D. Annu. Rep. NMR Spectrosc. 1979, 9, 287

$$
\begin{gathered}
\mathrm{C}_{2} \mathrm{H}_{1,} \\
\mathrm{CH}_{3}-\underset{\mathrm{Si}}{\stackrel{\mathrm{S}}{l}-\mathrm{OH}},
\end{gathered}
$$<smiles>CC[Si](C)(C)O[Na]</smiles><smiles>CCCCCCCCC</smiles>

$$
\begin{gathered}
\mathbf{M}^{\mathbf{0}} \\
\mathrm{C}_{8} \mathrm{H}_{11} \\
\mathrm{CH}_{3}-\mathrm{Si}-\mathrm{OH} \\
\dot{\mathrm{OH}}
\end{gathered}
$$

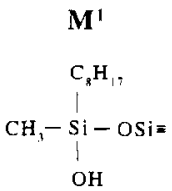<smiles>CCCCCCC(C)(O)O[Si](C)(O)CC</smiles>

$$
\begin{gathered}
\text { D }^{0} \\
\mathrm{C}_{8} \mathrm{H}_{1}, \\
\left.\right|_{\mathrm{Si}}-\mathrm{OH} \\
\mathrm{OH}
\end{gathered}
$$

$\mathbf{T}^{\mathbf{0}}$

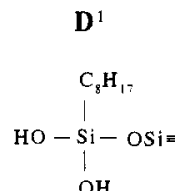

\begin{tabular}{|c|c|c|c|c|}
\hline methoxysilane & $\delta(\mathrm{ppm})$ & hydroxysilane & $\delta(\mathrm{ppm})$ & $\Delta \delta$ \\
\hline $\begin{array}{l}\left(\mathrm{CH}_{3}\right)_{3} \mathrm{SiOCH}{ }_{3} \\
\left(\mathrm{CH}_{3}\right)_{2} \mathrm{Si}\left(\mathrm{OCH}_{3}\right)_{2} \\
\left(\mathrm{CH}_{3}\right)_{\mathrm{Si}\left(\mathrm{OCH}_{3}\right)_{3}} \\
\mathrm{Si}\left(\mathrm{OCH}_{3}\right)_{4}\end{array}$ & $\begin{array}{r}+17 \\
-2 \\
-41 \\
-79\end{array}$ & $\begin{array}{l}\left(\mathrm{C}_{8} \mathrm{H}_{17}\right)\left(\mathrm{CH}_{3}\right)_{2} \mathrm{SiOH} \\
\left(\mathrm{C}_{8} \mathrm{H}_{17}\right)\left(\mathrm{CH}_{3}\right) \mathrm{Si}(\mathrm{OH})_{2} \\
\left(\mathrm{C}_{8} \mathrm{H}_{17}\right) \mathrm{Si}(\mathrm{OH})_{3} \\
\mathrm{Si}(\mathrm{OH})_{4}\end{array}$ & $\begin{array}{r}-1 \\
-14 \\
-44 \\
-70\end{array}$ & $\begin{array}{r}-18 \\
-12 \\
-3 \\
+9\end{array}$ \\
\hline
\end{tabular}

$\mathbf{T}^{1}$

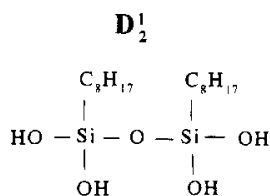

$\mathbf{T}_{2}^{1}$
Figure 11. Molecular structures of the detected ligand species.

ppm under the present experimental conditions. (Upon addition of the native silica to an equilibrium suspension of a model chlorosilane, the chemical shift of the hydroxysilanes is seen to shift by about $+1.5 \mathrm{ppm}$, probably due to less extensive ionization as the dissolution of silicate particles "consumes" sodium hydroxide from solution and the base/ silane ratio is decreased.) The dialkyldihydroxysilanes in 6 $\mathrm{M} \mathrm{NaOH}$ in $\mathrm{MeOH} / \mathrm{H}_{2} \mathrm{O}(50 / 50 \mathrm{v} / \mathrm{v})$ are shielded by about 12 ppm from their dialkoxy analogues, where one might expect a larger difference because of the difunctionality. We assume that an increased hydrogen-bonding capability of dialkyldihydroxysilanes can explain the smaller upfield shift. Kononov et al. state that the chemical shift of alkali metal organosilanols is largely determined by the polarity of the $\mathrm{Si}-\mathrm{O}$ bond, giving rise to an upfield shift upon increasing polarity. ${ }^{26}$ Coordination of water to the difunctional ligand silane particle (i.e., the formation of hydrogen bonds) weakens the polarity of both $\mathrm{Si}-\mathrm{O}$ bonds, which explains the smaller upfield shift for the dihydroxysilane. Finally, n-octyltrihydroxysilane is shielded by $3 \mathrm{ppm}$ from its trimethoxy analogue, and altogether the trend in the differences in chemical shift between the alkylalkoxy-and the alkylhydroxysilanes displayed in Table 4 is consistent, supporting the foregoing assignments.

\section{CONCLUSIONS}

From the results of this study it can be concluded that the mechanism through which a RP-HPLC phase in contact with basic solvent media deteriorates depends largely on the

(26) Kononov, O. V.; Erusalimskii, G. B.; Lazarev, S. Ya.; Lobkov, V. D. J. Gen. Chem. USSR (Engl. Transl.) 1991, 61, 2100. 
solubility of the individual silane structures at its surface. As shown, octadecyl ligand silanes are insoluble in the relatively polar $6 \mathrm{M} \mathrm{NaOH}$ in $\mathrm{MeOH} / \mathrm{H}_{2} \mathrm{O}(50 / 50 \mathrm{v} / \mathrm{v})$ solution, and any octadecyl phase (mono-, di-, or trifunctional) therefore seems to deteriorate through dissolution of the underlying silica substrate. This conclusion is valid only for the $\mathrm{MeOH} /$ $\mathrm{H}_{2} \mathrm{O}$ ratio used in this study, because there is ample evidence that the solvent composition has a great influence on the bonded-phase structure. Several authors postulated that the organization of alkyl ligands on a densely covered silica surface changes from a collapsed state at low percentages of organic modifier to an extended state at high percentages of organic modifier. ${ }^{27-29}$ This should change the shielding properties of the alkyl chains at different solvent compositions which, in turn, could change the degradation mechanism. Generally, the solubility of octyl ligand silanes decreases in the order mono- $>$ di- $>$ trifunctional. This is reflected in the observed dissolution patterns of the corresponding silica phases: after monofunctional octyl phases are dissolved, mostly monomeric ligand silanes are observed; difunctional octyl phases initially appear to release ligand structures attached to a small silica

(27) Lochmüller, C. H.; Hunnicutt, M. L.; Mullaney, J. F. J. Phys. Chem. 1985, $89,5770$.

(28) Carr, J. W.; Harris, J. M. Anal. Chem. 1987, 59, 2546.

(29) Bliesner, D. M.; Sentell, K. B. J. Chromatogr. 1993, 631, 23. backbone particle; and, finally, trifunctional octyl phases resemble octadecyl phases, probably because the great tendency of trifunctional silane particles to polymerize inhibits large-scale dissolution of monomeric ligand particles.

It should be borne in mind that the above results were obtained through a model dissolution study in which experimental circumstances differ considerably from those used in everyday chromatography. No difference could be observed between stationary phases stemming from the treated or the untreated silica substrate, nor were there any significant differences in the observed dissolution rates. Nevertheless, the results indicate that the use of alkylsilane reagents with bulky side groups or polymeric derivatization reagents may provide more stable RP-HPLC phases for two reasons. First, the solubility of the surface structures is decreased, and second, the silica surface is likely to be shielded more effectively from intense contact with aggressive eluents.

\section{ACKNOWLEDGMENT}

Dr. Friedhelm Eissenbeiss (E. Merck, Darmstadt, Germany) is gratefully acknowledged for donating the silicabased reversed phases used in this study.

Received for review March 30, 1994. Accepted July 24, 1994.

- Abstract published in Advance ACS Abstracts, September 15, 1994. 